\title{
MESSAGE
}

\section{IEICE Transactions on Communications: Editor's Message}

The members of the editorial committee of the IEICE Transactions on Communications change at the beginning of June annually for IEICE's new fiscal year. It is my great pleasure to assume the position of Editor-in-Chief (EiC) of the transactions and to serve a couple of years in the committee. I first stepped into this committee in 2002 as one of the Associate Editors whom the editorial committee added, not took turns. This buildup was made due to very rapid growth of applications to the transactions, especially from Asian countries. Now in these a few years, thanks to a lot of authors and their contributions, we have quite a lot of, more than 600 applications a year now; a volume of the transactions carries around 200 papers.

I think, however, that our committee should improve the IEICE Trans. Commun. at some points: fast review and wide circulation, for better quality of papers and higher impacts to the community in the technical field of communications. It is appreciated that our former EiCs and Editors together with the editorial board of the Communications Society of IEICE have continuously made a lot of efforts for this decade: discontinuing the Letter category and establishing an online Letter journal ComEX, adopting a new paper category Position Paper, beginning advance publication, and revising the copyright policy so that the authors can upload the PDF files of their published papers to servers. I think it is owing to these measures and their efforts that the impact factor is recently increasing a little. I, together with all Editors and Associate Editors, will continue to improve or kaizen the IEICE Trans. Commun. for our authors and readers. I hope this transactions will be more powerful and comfortable academic space for you to present your study, and an excellent knowledgebase for your research and development.

In closing, I would deeply thank Prof. Shoji Kasahara, the former EiC, and the former Editor, Prof. Takuji Tachibana for their dedicated efforts to maintain and improve the transactions. Prof. Eiji Okamoto and Prof. Go Hasegawa remain on the editorial board, and Prof. Satoshi Ohzahata has joined us as a new Editor. On behalf of the board, I also give my thanks to all the Associate Editors and reviewers as well as all the authors and readers for their lots of work and contributions. As EiC, I will do my best together with all the Editors and Associate Editors of the editorial committee. Your contribution is the most important. I hope to receive more submissions of your excellent or remarkable work.

Makoto Taromaru, Editor-in-Chief

\footnotetext{
Makoto Taromaru (Senior Member) received the B.E. and M.E. degrees in electronics engineering from the Tokyo Institute of Technology in 1985 and 1987, respectively, and the Ph.D. degree from Kyushu Institute of Technology, Fukuoka, in 1997. In 1987, he joined Kyushu Matsushita Electric Corporation, a company of Panasonic, where he worked on the development of cellular phones, the personal handy-phone system (PHS), and other digital cordless telephone systems. Between 2001 and 2004, he was with the Faculty of Engineering, Kyushu Sangyo University as an Associate Professor in the Department of Electrical Engineering. From 2004 to 2010, he was with ATR Wave Engineering Laboratories, Kyoto, and was the head of the Department of Wireless Communication Systems. Since 2010, he has been with the Department of Electronics and Computer Science at Fukuoka University, where he is currently a Professor. He served as an Editor of the IEICE Transactions on Communications and the IEICE Communications Express during 2006-2008 and 2013-2015 respectively. He received Distinguished Contributions Award from IEICE Communications Society in 2005 and 2008. His research interests include radio communication systems, especially on transceiver architecture and radio signal processing. Dr. Taromaru is a member of IEEE.
} 